\title{
Synthesis of phosphorothioates using thiophosphate salts
}

Babak Kaboudin ${ }^{*}$ and Fatemeh Farjadian

\section{Full Research Paper}

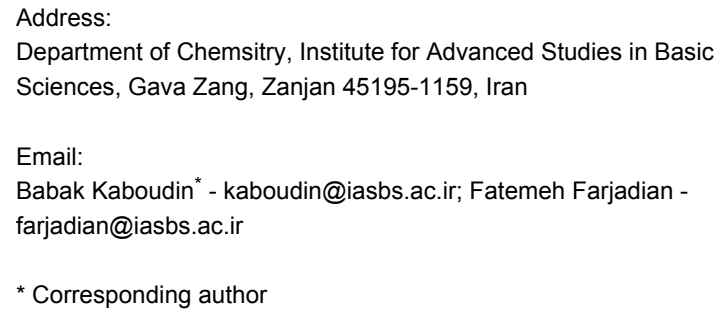

Beilstein Journal of Organic Chemistry 2006, 2, No. 4. doi:10.1186/1860-5397-2-4

Received: 10 December 2005

Accepted: 16 March 2006

Published: 16 March 2006

() 2006 Kaboudin and Farjadian; licensee Beilstein-Institut. License and terms: see end of document.

\begin{abstract}
Reactions of $O, O^{\prime}$-dialkyl thiophosphoric acids with alkyl halides, in the presence of a base, provide a direct synthetic route to phosphorothioates via $O, O^{\prime}$-dialkyl thiophosphate anion formation. Studies on the reaction of ambident nucleophile ammonium $O, O^{\prime}-$ diethyl thiophosphate with benzyl halides and tosylate in different solvents show that only $S$-alkylation is obtained. Reaction of this ambident nucleophile with benzoyl chloride (a hard electrophile), gave the $O$-acylation product. A simple, efficient, and general method has been developed for the synthesis of phosphorothioates through a one-pot reaction of alkyl halides with the mixture of diethyl phosphite in the presence of triethylamine/sulfur/and acidic alumina under solvent-free conditions using microwave irradiation.
\end{abstract}

\section{Introduction}

Organophosphorus compounds have found a wide range of application in the areas of industrial, agricultural, and medicinal chemistry owing to their biological and physical properties as well as their utility as synthetic intermediates. [1] The synthesis of phosphate esters is an important objective in organic synthesis, since they have found use in the preparation of biologically active molecules, and also versatile intermediate in synthesis of amides and esters. [2-4] Among the phosphate esters, phosphorothioate derivatives are of interest as effective pesticides. [5-8] In recent years a number of phosphorothioates have been introduced as potential chemotherapeutic agent. [9-12] Despite their wide range of pharmacological activity, industrial and synthetic applications, the synthesis of phos- phorothioates has received little attention. The following methods, not generally applicable, have been reported in the literature: (i) reaction of dialkyl phosphites with sulfenyl chlorides,[13] sulfenyl cyanides,[14] thiosulfonates,[15,16] disulfides,[17] and sulfur, [18-21] (ii) condensation of phosphorchloridate with thiols [22-26] and (iii) redox-type reactions of phosphorus triesters with thiols in the presence of tellurium (IV) chloride. $[27,28]$ However, all of these methods have problems, including drastic reaction conditions and also some severe side reactions. Surface-mediated solid phase reactions are of growing interest [29-35] because of their ease of set-up, workup, mild reaction conditions, rate of the reaction, selectivity, high yields, lack of solvent and the low cost of the reactions in 
comparison with their homogeneous counterparts. The application of microwave energy to accelerate organic reactions is of increasing interest and offers several advantages over conventional techniques. [36] Synthesis of molecules that normally require long reaction times, can be achieved conveniently and very rapidly in a microwave oven. As a part of our efforts to explore the utility of surface-mediated reactions for the synthesis of organophosphorus compounds, [37-48] we report a new method for the preparation of phosphorothioates by reaction of diethyl phosphite with alkyl halides in the presence of a mixture of ammonium acetate/sulfur/alumina under solvent-free conditions using microwave irradiation which produces high yields of phosphorothioates (Scheme 1).

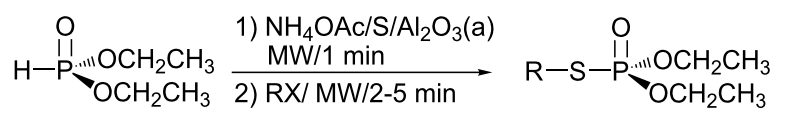

Scheme 1: Synthesis of phosphorothioates using microwave irradiation

\section{Results and Discussion}

Recently we have found that ammonium $O, O^{\prime}$-diethyl thiophosphate can be obtained by reaction of diethylphosphite in the presence of a mixture of ammonium acetate/sulfur/acidic alumina under solvent-free conditions using microwave irradiation. [49] This reagent can be used as an efficient reagent for the conversion of epoxides to thiiranes. This ambident nucleophile has two potentially attacking atoms $(S$ or $O)$ and can attack with either of them, depending on conditions, and mixtures are often obtained in the reaction with electrophilic centers (Scheme 2). [50]

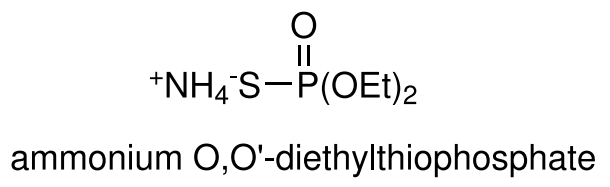<smiles>CCCPOP(=S)(OCC)OCC</smiles>

\section{ambident nucleophile}

Scheme 2: Ambident nucleophile ammonium $O, O^{\prime}$-diethylthiophosphate

We have found that the reaction of diethyl phosphite with alkyl halides in the presence of a mixture of ammonium acetate/ sulfur/alumina under solvent-free conditions using microwave irradiation produces high yields of phosphothioates ( $S$-alkylation, Scheme 1). [44] We decided to investigate the reaction of this ambident nuclophile under different conditions (different leaving groups and solvents).

Firstly, we introduce a novel method for large-scale synthesis of ammonium $O, O^{\prime}$-diethyl thiophosphate. The reaction of sulfur with diethylphosphite in the presence of ammonium hydrogen carbonate under reflux condition in a solvent mixture of ethyl acetate and diethyl ether $(1: 1)$ gave ammonium $O, O^{\prime}$-diethyl thiophosphate in quantitative yield (Scheme 3).

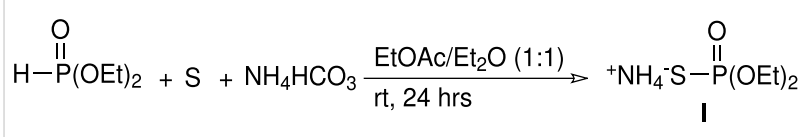

Scheme 3: Synthesis of ammonium O,O'-diethyl thiophosphate

The results of the reaction of this reagent with benzyl bromide, chloride and tosylate in different aporotic and protic solvents show that $S$-benzyl $O, O^{\prime}$-diethyl phosphorothioate ( $S$-alkylation) was formed as sole product (Scheme 4).

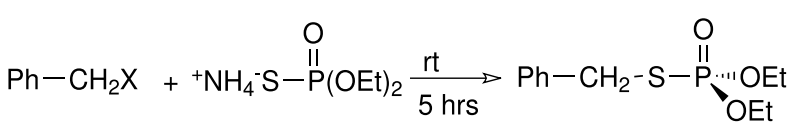

$\mathrm{X}=\mathrm{Br}-, \mathrm{Cl}-$, and $\mathrm{TsO}-$

Solvent: DMF, DMSO, Acetonitrile, $\mathrm{EtOH}$, and $\mathrm{MeOH}$

Scheme 4: Solvent and leaving group effects on the synthesis phosphorothioates

We conclude here that changing of leaving group and use of different media gives no $O$-alkylation product (i.e. changing from soft to hard leaving group and aprotic to protic solvent). Although ammonium $O, O^{\prime}$-diethyl thiophosphate is a potential ambident nucleophile, only its soft center is reactive in this case.

Recently the synthesis of $S$-thioacyl dithiophosphates has been reported as an efficient and chemoselective thioacylating agent using the reaction of acyl chlorides with dithiophosphoric acid in the presence of pyridine or triethylamine. [51-53] In another study we decided to investigate the reaction of the ambident nucleophile ammonium $O, O^{\prime}$-diethyl thiophosphate salt with acyl chlorides. Reaction of ammonium $O, O^{\prime}$-diethyl thiophosphate with benzoyl chloride, as a model compound, in acetonitrile gave benzamide as the major product (Scheme 5). 
Table 1: Reaction of alkyl halides and tosylates in the presence of a mixture of triethyl amine/sulfure/alumina with diethylphosphite under solvent-free conditions

\begin{tabular}{lllll} 
2 & $\mathrm{R}$ & $\mathrm{X}$ & Reaction Time (min) & Yield \%a \\
\hline a & $\mathrm{PhCH}_{2}$ & $\mathrm{Br}$ & 3 & 62 \\
a & $\mathrm{PhCH}_{2}$ & $\mathrm{OTs}$ & 3 & 67 \\
b & $\mathrm{PhCH}_{2} \mathrm{CH}_{2}$ & $\mathrm{Br}$ & 2 & 72 \\
c & $p-\mathrm{NO}_{2} \mathrm{C}_{6} \mathrm{H}_{4} \mathrm{CH}_{2}$ & $\mathrm{Br}$ & 4 & 70 \\
c & $p-\mathrm{NO}_{2} \mathrm{C}_{6} \mathrm{H}_{4} \mathrm{CH}_{2}$ & $\mathrm{OTs}$ & 5 & 83 \\
d & $o-\mathrm{MeC}_{6} \mathrm{H}_{4} \mathrm{CH}_{2}$ & $\mathrm{Br}$ & 3 & 65 \\
d & $o-\mathrm{MeC}_{6} \mathrm{H}_{4} \mathrm{CH}_{2}$ & $\mathrm{Cl}$ & 3 & 65 \\
e & $p-\mathrm{ClC}_{6} \mathrm{H}_{4} \mathrm{CH}_{2}$ & $\mathrm{OTs}$ & 2 & 67 \\
f & $m-\mathrm{ClC}_{6} \mathrm{H}_{4} \mathrm{CH}_{2}$ & $\mathrm{OTs}$ & 2 & 55 \\
g & $p-\mathrm{MeC}_{6} \mathrm{H}_{4} \mathrm{CH}_{2}$ & $\mathrm{Br}$ & 4 & 62 \\
h & $1-\mathrm{Butyl}_{\text {I }}$ & $\mathrm{Br}$ & 2 & 76 \\
\hline & $1-\mathrm{Hexyl}$ & $\mathrm{Cl}$ & 5 & 75 \\
\hline
\end{tabular}

a: Isolated Yields
We conclude that replacement of benzyl with benzoyl group (hard electrophilic center) gives the $O$-acylation product.

As a part of our efforts to explore the utility of surface-mediated reactions for the synthesis of organophosphorus compounds, [16-18] herein we report a new method for the preparation of phosphorothioates by reaction of diethyl phosphite with alkyl halides in the presence of a mixture of triethylamine/sulfur/alumina under solvent-free conditions using microwave irradiation. We found that a mixture of alumina, sulfur, diethylphosphite and triethylamine under microwave irradiation gave triethylammonium $O, O^{\prime}$-diethyl thiophosphate that can be used for the synthesis of phosphorothioates under solvent free conditions (Scheme 7, Table 1). As shown in Table 1, a wide range of alkyl halides in the presence triethylamine/ sulfur/alumina reacted with diethyl phosphite, giving the required products $\mathbf{2}$ in moderate to good yields.

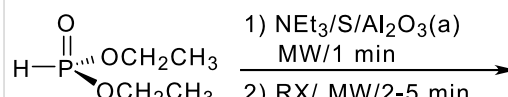

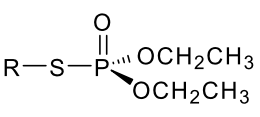

2

Scheme 7: Synthesis of phosphorothioates using triethylammonium $O, O^{\prime}$-diethyl thiophosphate using microwave irradiation.
Scheme 5: Reaction of ammonium O,O'-diethyl thiophosphate with benzoyl chloride

Benzoyl chloride reacts with ammonia (from ammonium $O, O^{\prime}-$ diethyl thiophosphate) faster than anion $O, O^{\prime}$-diethyl thiophosphate to give benzamide. All efforts for solving this problem failed and in all cases benzamide was obtained as the major product.

We decided to replace this ammonium ion with a triethyl ammonium ion and then to study the reaction of new salt with benzoyl chloride. Triethylammonium $O, O^{\prime}$-diethyl thiophosphate was obtained by reaction of diethylphosphite, sulfur and triethyl amine. [54-57] We found that reaction of triethylammonium $O, O^{\prime}$-diethyl thiophosphate with benzoyl chloride gave benzoyl $O, O^{\prime}$-diethyl phosphorothioate with $O$-acylation product (Scheme 6).

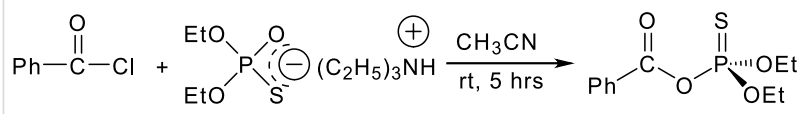

II

Scheme 6: Reaction of triethylammonium $O, O^{\prime}$-diethyl thiophosphate with benzoyl chloride
In summary, a simple work-up, low consumption of solvent, fast reaction rates, mild reaction conditions, good to excellent yields, relatively clean reactions with no tar formation make these methods an attractive and a useful contribution to present methods for the preparation of phosphorothioates. Studies on the reaction of ambident nucleophile ammonium $O, O^{\prime}$-diethyl thiophosphate with benzyl halides and tosylate in different solvents show that only $S$-alkylation will be obtained as sole product. Reaction of this ambident nucleophile with benzoyl chloride (hard electrophilic center), gave the $O$-acylation product.

\section{Supporting Information}

\section{Supporting Information File 1}

The additional file contains full experimental details [http://www.beilstein-journals.org/bjoc/content/ supplementary/1860-5397-2-4-S1.doc]

\section{Acknowledgments}

The Institute for Advanced Studies in Basic Sciences (ASBS) is thanked for supporting this work. 


\section{References}

1. Engel, R. Chem. Rev. 1977, 77, 349. doi:10.1021/cr60307a003

2. Deloude, L.; Laszlo, P. J. Org. Chem. 1996, 61, 6360. doi:10.1021/ jo960633p

3. Varma, R. S.; Meshram, H. M. Tetrahedron Lett. 1997, 38, 7973. doi:10.1016/S0040-4039(97)10143-5

4. Smyth, M. S.; Ford, H., Jr.; Burke, T. R., Jr. Tetrahedron Lett. 1992, 33, 4137-4140. doi:10.1016/S0040-4039(00)74672-7

5. Burke, T. R.; Smyth, M. S.; Nomizu, M.; Otaka, A.; Roller, P. P. J. Org. Chem. 1993, 58, 1336. doi:10.1021/jo00058a009

6. Burke, T. R.; Smyth, M. S.; Otaka, A.; Roller, P. P. Tetrahedron Lett. 1993, 34, 4125. doi:10.1016/S0040-4039(00)60508-7

7. Smyth, M. S.; Burke, T. R. Tetrahedron Lett. 1994, 35, 551. doi:10.1016/S0040-4039(00)75835-7

8. Benayound, F.; Hammond, G. B. Chem. Commun. 1996, 1447. doi:10.1039/cc9960001447

9. Fest, C.; Schmidt, K.-J. The Chemistry of Organophosphorus Pesticides; Springer Verlag: Berlin Heidelberg New York, 1982.

10. Uhlman, E.; Peyman, A. Chem. Rev. 1990, 90, 543. doi:10.1021/ cr00102a001

11. Stein, C. A.; Cheng, Y. C. Science 1993, 261, 1004. doi:10.1126/ science.8351515

12. Crooke, S. T.; Bennett, C. F. Annu. Rev. Pharmacol. Toxicol. 1996, 36, 107. doi:10.1146/annurev.pa.36.040196.000543

13. Elzagheid, M. I.; Mattila, K.; Oivanen, M.; Jones, B. C. N. M.; Cosstick, R.; Lonnberg, H. Eur. J. Org. Chem. 2000, 1987. doi:10.1002/(SICI)1099-0690(200005)2000:10<1987::AIDEJOC1987>3.0.CO;2-X

14. Yoshido, M.; Maeda, T.; Sugiyama, H. Chem. Abstr. 1967, 66, $115455 \mathrm{~g}$.

15. Fokin, A. V.; Kolomiets, A. F.; Iznoskova, M. G. Izv. Akad. Nauk. SSSR, Ser. Khim. 1974, 2837-2840. Chem. Abstr., 1975, 82, 97323m.

16. Schrader, G. Neutral esters of thiolphosphoric acid. US Patent 2,597,534, May 20, 1952. Chem. Abstr., 1953, 47, 4357g.

17. Michalski, J.; Modro, T.; Wieczorkowski, J. J. Chem. Soc. 1960, 1665. doi:10.1039/jr9600001665

18. Michalski, J.; Wasiak, J. J. Chem. Soc. 1962, 5056. doi:10.1039/ jr9620005056

19. Michalski, J.; Wieczorkowski, J.; Wasiak, J.; Pliszka, B. Rocz. Chem. 1959, 33, 247. Chem. Abstr. 1959, 53, 17884i

20. Harvey, R. G.; Jacobson, H. I.; Jensen, E. V. J. Am. Chem. Soc. 1963, 85, 1618. doi:10.1021/ja00894a018

21. Torii, S.; Tanaka, H.; Sayo, N. J. Org. Chem. 1979, 44, 1938.

22. Sato, Z.; Shimizu, S.; Shimizu, F.; Kusano, S.; Takagi, K.; Imamiya, Y. Verfahren zur Herstellung von O,O-Dialkyl-S-benzyl-thiophosphaten. Ger. Offen. 2601 532, August 5, 1976.

Chem. Abstr. 1976, 85, 123628y.

23. Hashimoto, T.; Ohkubo, T. Chem. Abstr. 1977, 87, 134503w.

24. Schrader, G.; Lorenz, W. Benzyl esters of thiophosphoric acids and their production. US Patent 2,862,017, November 25, 1958. Chem. Abstr. 1960, 54, 1437i.

25. Farbenfabriken Bayer Akt.-Ges. Process for the production of ThiolPhosphoric Acid Esters. British Patent 814332, June 3, 1959. Chem. Abstr. 1960, 54, 17330b.

26. Kabachnik, M. I.; Mastrykova, T. A. Zh. Obshch. Khim. 1955, 25, 1924 Chem. Abstr. 1956, 50, 8499d.
27. Schrader, G.; Lorenz, W. Schädlingsbekämpfungsmittel. German Patent 817 057, August 23, 1951.

Chem. Abstr. 1954, 48, 6643c.

28. Sallmann, R. Verfahren zur Herstellung von Phosphor enthaltenden organischen Verbindungen. Swiss Patent 324980, November 30, 1957. Chem. Abstr. 1958, 52, 14960a.

29. Fadel, A.; Yefash, R.; Saluan, J. Synthesis 1987, 37. doi:10.1055/s1987-27833

30. Rosini, G.; Galarini, R.; Marotta, E.; Righi, R. J. Org. Chem. 1990, 55, 781. doi:10.1021/jo00290a001

31. Kodomari, M.; Sakamoto, T.; Yoshitomi, S. J. Chem. Soc., Chem. Commun. 1990, 701. doi:10.1039/c39900000701

32. Kropp, P. J.; Daus, K. A.; Crawford, S. D.; Tubergren, M. W.; Kepler, K. D.; Craig, S. L.; Wilson, V. P. J. Am. Chem. Soc. 1990, 112, 7433. doi:10.1021/ja00176a075

33. Hondrogiannis, G.; Pagni, R. M.; Kabalka, G. W.; Anisoki, P.; Kurt, R. Tetrahedron Lett. 1990, 31, 5433. doi:10.1016/S0040-4039(00)97865-1

34. Pantney, H. K. Tetrahedron Lett. 1991, 32, 2259. doi:10.1016/S00404039(00)79696-1

35. Pauter, F.; Daudon, M. Tetrahedron Lett. 1991, 32, 1457. doi:10.1016/ 0040-4039(91)80357-C

36. Caddick, S. Tetrahedron 1995, 55, 10403. doi:10.1016/00404020(95)00662-R

37. Sardarian, A. R.; Kaboudin, B. Synth. Commun. 1997, 27, 543.

38. Sardarian, A. R.; Kaboudin, B. Tetrahedron Lett. 1997, 38, 2543. doi:10.1016/S0040-4039(97)00396-1

39. Kaboudin, B. Tetrahedron Lett. 2000, 41, 3169. doi:10.1016/S00404039(00)00323-3

40. Kaboudin, B. Chem. Lett. 2001, 880. doi:10.1246/cl.2001.880

41. Kaboudin, B.; Nazari, R. Tetrahedron Lett. 2001, 42, 8211. doi:10.1016/S0040-4039(01)01627-6

42. Kaboudin, B.; Nazari, R. Synth. Commun. 2001, 31, 2245. doi:10.1081/ SCC-100104822

43. Kaboudin, B.; Balakrishna, M. S. Synth. Commun. 2001, 31, 2773. doi:10.1081/SCC-100105324

44. Kaboudin, B. Tetrahedron Lett. 2002, 43, 8713. doi:10.1016/S00404039(02)02136-6

45. Kaboudin, B. Tetrahedron Lett. 2003, 44, 1051. doi:10.1016/S00404039(02)02727-2

46. Kaboudin, B.; Rahmani, A. Synthesis 2003, 2705. doi:10.1055/s-200342427

47. Kaboudin, B.; Norouzi, H. Synthesis 2004, 2035. doi:10.1055/s-2004829176

48. Kaboudin, B.; Saadati, F. Synthesis 2004, 1249. doi:10.1055/s-2004822350

49. Kaboudin, B.; Norouzi, H. Tetrahedron Lett. 2004, 45, 1283. doi:10.1016/j.tetlet.2003.11.099

50. Frey, P. A.; Sammons, R. D. Science 1985, 228, 541. doi:10.1126/ science. 2984773

51. Doszczak, L.; Rachon, J. Chem. Commun. 2000, 2093. doi:10.1039/ b005911k

52. Doszczak, L.; Rachon, J. J. Chem. Soc., Perkin Trans. 1 2002, 1271. doi:10.1039/b201233b

53. Doszczak, L.; Rachon, J. Synthesis 2002, 1047. doi:10.1055/s-200231957

54. Chojnowski, J.; Cypryk, M.; Fortuniak, W.; Michalski, J. Synthesis 1977, 683. doi:10.1055/s-1977-24532

55. Pogosyan, A. S.; Torgomyan, A. M.; Indzhikyan, M. G. J. Gen. Chem. USSR 1990, 60, 1383. 
56. Nasser, F. A. K.; Mastrukova, T. A. J. Organomet. Chem. 1983, 244 ,

17. doi:10.1016/S0022-328X(00)98630-3

57. Desforges, E.; Grysan, A.; Oget, N.; Sindt, M.; Mieloszynski, J. L.

Tetrahedron Lett. 2003, 44, 6273-6276.

\section{License and Terms}

This is an Open Access article under the terms of the Creative Commons Attribution License

(http://creativecommons.org/licenses/by/2.0), which permits unrestricted use, distribution, and reproduction in any medium, provided the original work is properly cited.

The license is subject to the Beilstein Journal of Organic Chemistry terms and conditions:

(http://www.beilstein-journals.org/bjoc)

The definitive version of this article is the electronic one which can be found at:

doi:10.1186/1860-5397-2-4 